\title{
Por uma poética reinventada: Manoel de Barros e Yves Bonnefoy
}

Leila de Aguiar Costa

Universidade Federal de São Paulo

Foudre qui dort encore,

Les traits en paix,

Souriante comme avant

$Q u^{\prime}$ il y ait langage

Yves Bonnefoy

Eu queria avançar para o começo.

Chegar ao criançamento das palavras [...] Quando a criança garatuja o verbo para falar o que não tem

Manoel de Barros

aproximação proposta no título pode surpreender... Mas,
a se percorrer atentamente a produção poética de Manoel
de Barros e de Yves Bonnefoy, fica evidente que os já quase 
se dará como tarefa escapar à maldição de uma linguagem que distorce o laço entre os três polos do signo, abolindo a relação entre significante/significado de um lado e referente de outro.

Nesse sentido, tomar-se-á como moldura e baliza da poética dos dois autores a proposta recentemente enunciada por Yves Bonnefoy: segundo ele,impõe-se compreender o fazer literário não mais como uma "metonímia significante" - que aprisionaria a poesia no registro do conceitual - mas, doravante, como uma "metonímia poética", caminho pelo qual "a percepção do imediato, do inconcluso do real, do Um, penetra nas redes conceituais que tecem aquela imagem do mundo em que vivemos e que nos aliena"1 ${ }^{1}$. Recorrer à metonímia poética significará redescobrir uma contiguidade não mais com outro significante da língua, mas diretamente com o referente reencontrado. Renasceria, assim, o laço perdido entre as palavras e o mundo. Ressurgiriam, por isso mesmo, coisas, objetos, seres que vivem no real, sob dimensões diversas, e que convocam e interpelam diversas percepções.

\section{I.Aprender a ouvir a própria linguagem}

Parece inegável que a pedra-de-toque das poéticas bonnefidiana e barrosiana é a recuperação da relação, perdida, com o mundo. Se não se pode falar aqui de uma poética referencial, em um e em outro claramente se reconhece aquela recusa das "velhas fanfarras de heroísmo" 2 de que zomba Rimbaud. Em

${ }^{1}$ BONNEFOY, 2011, p.444.

${ }^{2}$ Como se lê, em «Barbare », poema que integra Illuminations : "Bien après les jours et les saisons, et les êtres et les pays, Le pavillon en viande saignante sur la soie des mers et des fleurs arctiques; (elles n'existent pas.) Remis des vieilles fanfares d'heroïsme - qui nous attaquent encore le coeur et la tête" (RIMBAUD, 1999, p. 232). Pois que, justa e precisamente, ensina-nos Bonnefoy, "l'essentiel d'un Rimbaud se joue dans un rapport au monde, à la vie, désirée 'vraie 
Bonnefoy, a verdade das palavras - e não aquela de um Logos tirânico e autoritário - pertence às coisas, está inscrita nas cores e nos tons. Em Manoel de Barros, a verdade das palavras - e não aquela das "palavras já muito usadas, como velhas prostitutas, decaídas", mortas "por clichê" ${ }^{3}$ e, por inferência, aquela da poesia, pertence "aos bichos, aos vegetais", contamina-se "de árvores, de pássaros, de rãs" ${ }^{4}$. Em Manoel de Barros e em Yves Bonnefoy, a poesia dialoga inegavelmente com as pedras, com a res. Epifania, pois, do sensível. Epifania que encena a abertura para o mundo, seja ele natural, vegetal ou, mesmo, humano. Epifania que é ascensão, como bem expressa o poema "Ascensão" (Tratado geral das grandezas do ínfimo) de Manoel de Barros:

Depois que iniciei minha ascensão para a infância Foi que vi como o adulto é sensato!

Pois como não tomar banho nu no rio entre pássaros?

Como não furar lona de circo para ver os palhaços?

Como não ascender ainda mais até na ausência da voz?

(Ausência de voz é infantia, com t. em latim.)

Pois como não ascender até a ausência da voz -

Lá onde a gente pode ver o próprio feto do verbo ainda sem movimento.

Aonde a gente pode enxergar o feto dos nomes ainda sem penugens.

Por que não voltar a apalpar as primeiras formas da pedra. A escutar

Os primeiros pios dos pássaros. A ver

As primeiras cores do amanhecer.

Como não voltar para onde a invenção está virgem?

Porque não ascender de volta para o tartamudo! ${ }^{5}$

vie', que la pensée conceptuelle, seul instrument de la critique [...] ne peut explorer, étant par nature distraite des perceptions et besoins de finitude" (BONNEFOY, 2009, p. 9).

${ }^{3}$ BARROS, 2010, p.137.

${ }^{4}$ BARROS 2010, p.137.

${ }^{5}$ BARROS, 2010, p.409-410. 
"Ascender até a ausência da voz" - daquela voz que se perdeu nos meandros da língua, sempre autoritária, sempre coercitiva, e que, por isso mesmo, deixou de se fazer palavra -; "ver o feto dos nomes", antes mesmo de sua pertença à língua e a seus desmandos logorreicos. Regressar às origens é, em Manoel de Barros, recuperar o original para desinflacionar a invenção poética de tudo aquilo que a perdeu e a perverteu. Deixar o verbo, deixar a palavra encarnarem-se nas coisas e nos seres. Tal parece ser a lição do poema 2 de Retrato do artista quando coisa - em que a própria língua poética muda de feição, assume outras regras, em franca subversão da sintaxe da língua do coletivo:

Bom é corromper o silêncio das palavras.

Como seja:

1. Uma rã me pedra. (A rã me corrompeu para

Pedra. Retirou meus limites de ser humano e me ampliou para coisa. A rã se tornou o sujeito pessoal da frase e me largou no chão a criar musgos para tapete de insetos e de frades.)

2.Um passarinho me árvore. (O passarinho me transgrediu para árvore. Deixou-me aos ventos e às chuvas. Ele mesmo me bosteia de dia e me desperta nas manhãs.)

3. Os jardins se borboletam. (Significa que os jardins se esvaziaram de suas sépalas e de suas pétalas? Significa que os jardins se abrem agora só para o buliço das borboletas?)

Gosto de viajar por palavras do que de trem ${ }^{6}$.

${ }^{6}$ BARROS, 2010, p.358. O mesmo se lê no poema 3: "Há um cio vegetal na voz do artista./Ele vai ter que envesgar seu idioma ao ponto/de alcançar o murmúrio das águas nas folhas/das árvores./ 
Semelhante viagem é possível, em Manoel de Barros, a partir de uma palavra que, para dar conta da "imediatez do objeto", deve desfazer-se de um discurso já instituído e, por conseguinte, retornar a seu frescor original, próximo à infância ${ }^{7}$ - que é infância das palavras, descrita no "Livro de pré-coisas" (Lioro de pré-coisas) -:

Eu briguei naquele menino com uma pedra... Crianças desescrevem a língua. Arrombam as gramáticas. (Como um cálice lilás de beco!) ${ }^{8}$

Não terá mais o condão de refletir sobre as/ Coisas./Mas terá o condão de sê-las. / Não terá mais ideias: terá chuvas, tardes, ventos,/ Passarinhos... [...] (BARROS, 2010, p.359).

${ }^{7}$ Chame-se a atenção, a este respeito, para a relevância, marcante, da figura da infância e do infans na poesia de Manoel de Barros e de Yves Bonnefoy: a criança parece comparecer na obra de ambos como imagem da cena da escritura, cena de um antes-da-linguagem que é a língua das/de crianças, antes de toda nominação, de toda atribuição de signos arbitrários, antes de toda tagarelice - aquela que combate, justamente, a figura da criança taciturna da prosa poética bonnefidianna intitulada L'Amérique, e a figura do tartamudo do poema "Ascensão", de Manoel de Barros - sem contar os Bernardo, os Sabastião que povoam o universo poético barrosiano, crianças-árvore, crianças-pássaro... Reproduza-se a seguir, com proveito, certos versos do poema VIII de "Retrato quase apagado em que se pode ver perfeitamente nada", em que se expõem as prerrogativas dessa poesia balizada pelo infans: "Nas Metamorfoses, em duzentas e quarenta fábulas,/ Ovídio mostra seres humanos transformados em pedras, vegetais, bichos, coisas./Um novo estágio seria que os entes já transformados/ Falassem um dialeto coisal, larval, pedral etc./ Nasceria uma linguagem madruguenta, adâmica,/ edênica, inaugural -/Que os poetas aprenderiam -/desde que voltassem às/crianças que foram/Âs rãs que foram/Às pedras que foram. / Para voltar à infância, os poetas precisariam também de/ Reaprender a errar a língua (BARROS, 2010, p.265-266).

${ }^{8}$ BARROS, 2010, p.221. 
Em Yves Bonnefoy, trata-se de um retorno à presença, como ele muito bem esclarece em entrevista concedida a Pedro B. Rey: seu projeto é aquele de

fazer aparecer nas palavras o que chamo a presença das coisas: esta imediatez do objeto que nos prende com ela em uma experiência de unidade, onde se dissipa o 'eu', isto é, a ideia que se tem de si por causa dos preconceitos da linguagem. ${ }^{9}$

Isto equivale a dizer que se trata de um retorno à palavra pura, sem interferências da sintaxe e da épistémè. À poesia de torcer o pescoço da eloquência - segundo a célebre injunção de Paul Verlaine em sua Art poétique-, de declarar guerra ao conceito e ao pensamento conceitual, pois que rejeitam toda presença e toda finitude. Se o conceito é o autoritário, ele o éjustamente pelo fato de ser arbitrário. Apenas a "nova virgindade" da palavra, reencontrada, e que o poeta, depois de passar anos a fio "penteando e desarrumando as frases" ${ }^{10}$, finalmente "arruma num poema" - tal é a lição de Manoel de Barros ${ }^{11}$-, garante às coisas sua própria carne e aos seres sua própria carnação. Não por acaso, Yves Bonnefoy afirma a respeito dos perigos da representação, da mimesis multissecular que norteia a produção poética ocidental:

Pois as percepções, as representações, as figuras que são circunscritas por esse emprego da linguagem, por mais que esse emprego se interesse pelos aspectos mais concretos, pelos objetos mais sensoriais de sua atenção, não

${ }^{9}$ BONNEFOY, 2010, p. 342 : Faire apparaître dans les mots ce que j'appelle la présence des choses: cette immédiateté de l'objet qui nous prend avec elle dans une expérience d'unité où se dissipe le 'moi', c'est-à-dire l'idée que l'on a de soi du fait des préjugés du langage ». ${ }^{10}$ BARROS, 2010, p.305.

${ }^{11}$ BARROS, 1996, p.208. 
se aproximam, pois, destes últimos senão pela mediação das noções que ali se substituem, não têm relação em uma presença de coisa ou de ser senão com sua noção, com aquilo a que esta última se reduz no dicionário ou no catálogo; não se trata, pois, em seu caso, daquelas experiências da realidade imediata como nos acontece de experimentar na existência desperta [...]. ${ }^{12}$

A "experiência desperta" é aquela do hic et nunc, aquela que somente é possível sem a intervenção do conceito que afasta o homem de si mesmo, de sua experiência em si e no mundo:

Um conceito? Trata-se do nome que damos a um aspecto de uma coisa ou de um fenômeno; trata-se, pois, de uma abstração, da generalidade, e o discurso dos conceitos vai, pois, ser ele mesmo uma proposição geral, que nos incitará a esquecer de que somos seres que vivem aqui e agora, e por um tempo limitado". ${ }^{13}$

Desse conceito que, em O livro sobre nada, Manoel de Barros diz que devemos nos desvencilhar, pois que "Melhor que nomear

${ }^{12}$ BONNEFOY, 2010, p. 324 : «Car les perceptions, les représentations, les figures qui sont retenues par cet emploi du langage, aussi intéressé cet emploi soit-il par les aspects les plus concrets, les plus sensoriels des objets de son attention, n'abordent donc ces derniers que par le truchement des notions qui s'y substituent, n'ont rapport dans une présence de chose ou d'être qu'à sa notion, qu'à ce que celle-ci est réduite à être dans le dictionnaire ou le catalogue, il ne s'agit donc plus dans leur cas de ces expériences de la réalité immédiate comme il nous arrive d'en faire dans l'existence éveillée [...] »

${ }^{13}$ BONNEFOY, 2010, p. 442 : "Un concept, c'est le nom que nous donnons à un aspect d'une chose ou d'un phénomène, c'est donc une abstraction, de la généralité, et le discours des concepts va donc être luimême une proposition générale, qui nous incitera à oublier que nous sommes des êtres vivant ici et maintenant, et pour un temps limité » 
é aludir.Verso não precisa dar noção" ${ }^{14}$ Dessa nomeação, desse nome que, ainda em Manoel de Barros, empobrecem a imagem. É como ele mesmo diz no poema XIX do Livro das Ignorãças:

O rio que fazia uma volta atrás de nossa casa era a imagem de um vidro mole que fazia uma volta atrás de casa.

Passou um homem depois e disse: Essa volta que o rio faz por trás de sua casa se chama enseada.

Não era mais a imagem de uma cobra de vidro que fazia uma volta atrás de casa.

Era uma enseada.

Acho que o nome empobreceu a imagem. ${ }^{15}$

\section{II. "As coisas que não têm nome são mais pronunciadas por crianças"}

O poético em Manoel de Barros e Yves Bonnefoy somente se faz então possível pela recusa dos processos de nomeação. Não surpreende que um dos grandes poemas de Manoel de Barros, intitulado não por acaso "Despalavra" (Ensaios fotográficos), afirme que os

poetas podem ser pré-coisas, pré-vermes, podem ser pré-musgos.

Daqui vem que os poetas podem compreender o mundo sem conceitos. ${ }^{16}$

${ }^{14}$ BARROS, 2010, p.346.

${ }^{15}$ BARROS, 2010, p.303.

${ }^{16}$ BARROS, 2010, p.383. Este conceito que, segundo Bonnefoy, não se liga senão à essência e que despreza de certo modo a existência e suas coisas e suas figuras: "Y-a-t-il un concept d'un pas venant dans la nuit, d'un cri, de l'éboulement d'une pierre dans les broussailles? De l'impression que fait une maison vide? Mais non, rien n'a été gardé du réel que ce qui convient à notre repos" (BONNEFOY, 1992a, p.15). 
Um pré-mundo, pois, anterior àquele da palavra articulada, da organização discursiva que se esqueceu-ou que propositadamente repele - as origens. Esse retorno às origens é, em Manoel de Barros, alcançado pela conquista do "reino das imagens" - e, imagem, para o poeta mato-grossense, é "reino da despalavra". Em Yves Bonnefoy, é a recuperação para a escritura literária de suas "estruturas não-semânticas". É, então, o momento em que o Poeta desinventa e desescreve todos os sentidos arbitrariamente constituídos, todos os signos autoritariamente instituídos. E Manoel de Barros afirma, não sem certa compulsão assertiva - não é o que insinua o "daqui vem" entoado quase à maneira de uma cantilena? -, em "Despalavra" uma vez mais:

Daqui vem que todas as coisas podem ter qualidades humanas.

Daqui vem que todas as coisas podem ter qualidades de pássaros.

Daqui vem que todas as pedras podem ter qualidades de sapo.

Daqui vem que todos os poetas podem ter qualidades de árvore.

Daqui vem que os poetas podem arborizar os pássaros.

Daqui vem que todos os poetas podem humanizar as águas $[\ldots] .^{17}$

"Despalavra" que se confunde com o "delírio do verbo" (poema VII de Uma didática da invenção/O livro das ignorãças), que

estava no começo lá onde

A criança diz: Eu escuto a cor dos passarinhos.

A criança não sabe que o verbo escutar não funciona

Para cor, mas para som.

Então se a criança muda a função de um verbo, ele delira. ${ }^{18}$

${ }^{17}$ BARROS, 2010, p.383.

${ }^{18}$ BARROS, 2010, p.301. 
Os versos de "Despalavra" parecem ecoar na fala de uma das grandes personagens da prosa poética de Yves Bonnefoy, aquela de um não-ocidental que se entretém à beira-mar, em um porto em um Oriente não-nomeado-bem evidentemente-, com um Ocidental acometido de precisa enfermidade: ele perdeuse em exegeses balizadas por certo cratilismo falacioso e, por isso mesmo, não é mais capaz de compreender o simples e, por isso mesmo, verdadeiro, mundo que se lhe oferece aos olhos. Esse não-oriental aponta os caminhos da felicidade para aquele que não é mais capaz de compreender o idioma do mundo e, lateralmente, $\mathrm{o}$ idioma da poesia:

Desfazer a nomeação abusiva, soerguer com tal alavanca, o infinito, o arbitrário triste do signo, isto é, lavar a face do mundo, meu amigo, é se redescobrir respirando na respiração de tudo, silenciosa! Nós inventamos o segundo grau da palavra! ${ }^{19}$

A afirmação, quase com ares axiomáticos, do nãoocidental de "Deux ou d'autres couleurs" revela-se inquietação fundamental de um "ele" que nos revela a perversidade da nomeação em "De grands blocs rouges":

Que perda, nomear! Que engodo, falar! E que papel lhe é deixado, a ele que se interroga assim diante da terra que ama e que desejaria dizer, que papel sem fim para simplesmente não se fazer senão um com ela! ${ }^{20}$

${ }^{19}$ BONNEFOY, 1987, p. 81: « Défaire la dénomination abusive, lever par ce levier, l'infini, l'arbitraire triste du signe, mais c'est laver la face du monde, mon ami, c'est se retrouver respirant dans la respiration de tout, silencieuse! Nous avons inventé le second degré de la parole! » ${ }^{20}$ BONNEFOY, 1993, p. 44: "Quelle perte, nommer! Quel leurre, parler! Et quelle tâche lui est laissée, à lui qui s'interroge ainsi devant la terre qu'il aime et qu'il voudrait dire, quelle tâche sans fin pour simplement ne faire qu'un avec elle! » 
Confundir-se com a terra, Manoel de Barros o entendeu perfeitamente, e o pôs em execução em uma poesia que é errância na língua, "demência peregrina" da linguagem, pois que o idioma dos poetas está "enfiado nos mosquitos". ${ }^{21}$ Uma bela e luminosa metonímia poética de tal trabalho com a linguagem pode ser lida em "Bernardo" (Tratado geral das grandezas do ínfimo), o menino-árvore que deixa de sê-lo para se tornar - sonho eternamente acalentado por Bernardo e que de certa forma se transmuta em devaneio do poético barrosiano um arãquã. Ao leitor mais atento não escaparão as liberdades discursivas assumidas pelo poeta, justamente porque poeta, e porque do poeta se diz que ele tem

um parafuso de menos

sendo que o mais justo seria o de ter um parafuso trocado do que a

menos.

A troca de parafusos provoca nos poetas uma certa disfunção lírica. ${ }^{22}$

Lê-se, pois, em "Bernardo":

Bernardo já estava uma árvore quando eu o conheci.

Passarinhos já construíam casas na palha

Do seu chapéu.

Brisas carregavam borboletas para o seu

Paletó.

E os cachorros usavam fazer de poste as suas pernas.

Quando estávamos todos acostumados com aquele bernardo-árvore

Ele bateu asas e avoou.

${ }^{21}$ BARROS, 2010, p.265-266.

22 BARROS, 2010, p.399-400. 
Virou passarinho.

Foi para o meio do cerrado ser um arãquã.

Sempre ele dizia que o seu maior sonho era ser uma rãquã para compor o amanhecer. ${ }^{23}$

Não seria Bernardo a própria poesia, essa poesia descentrada dos significantes, essa poesia que se quer inscrita para além das "significações sempre relativas" - segundo os termos de Yves Bonnefoy em Entretiens sur la poésie - 1972-1990 24 -, essa poesia que é deslocamento dos sentidos? Bernardo é menino, é árvore, é "bernardo-árvore"; mas logo nãoé mais menino, tampouco árvore; é pássaro, é arãquã. ${ }^{25}$ Das figuras do menino, da árvore, do meninoárvore e do menino-pássaro, é todo um movimento escritural que se organiza, pelo intermédio das palavras e dos signos repensados - "repenteados" diria Barros -, para compor o poema. Poema que, à semelhança de um arãquã, abre-se para a luz, renovação a cada dia efetuada pela voz da ave e pela voz do poético.

Faça-se aqui a hipótese, quiçá arriscada, quiçá excessiva, de ver ecoar nesse "Bernardo" de Manoel de Barros algumas observações enunciadas por Yves Bonnefoy em seu texto intitulado "Le nuage rouge": "Que não se suprima o acaso [...] A encarnação, esse exterior do sonho, está bem próxima". ${ }^{26}$

Encarnação, eis o mote bonnefidiano da poesia. Bernardo, bernardo (des)figura e ao mesmo tempo (trans)figura o mundo, pois que o poema se movimenta no sentido de restaurar - ou, mesmo, instaurar - uma ordem graças a uma abertura, ali indiciada pela composição de um amanhecer pelo pássaro.

${ }^{23}$ BARROS, 2010, p.476.

${ }^{24}$ BONNEFOY, 1990, p.62.

${ }^{25}$ Não é demais lembrar que Manoel de Barros adota em seu poema a grafia pantaneira do nome dessa ave.

${ }^{26}$ BONNEFOY, 1999a, p.278-279 : «Qu'on n'abolisse plus le hasard [...] L'incarnation, ce dehors du rêve, est un bien proche ». 
"Bernardo" conciliaria, então, o que, em Bonnefoy, se põe em relação: a fidelidade ao mundo, reencontrado ou rememorado, e a função, evidentemente inaugural, atribuída à palavra, isto é, aquela de conferir vida ao mundo segundo o sentido.

\section{O poético como lugar do ser e da linguagem}

Importa, entretanto, repetir que tal palavra e sua função são mobilizadas não sem cautela - e não sem desconfiança - tanto por Manoel de Barros quanto por Yves Bonnefoy. Um e outro entendem que é relevante e incontornável dela tomar como se fosse uma primeira vez; para dela, justamente, recuperar tudo o que se perdeu em razão do autoritarismo do Logos e do conceito.

Essa palavra - nova - é aquela que desenha a forma de "um ser-no-mundo". ${ }^{27}$ Aquela que faz, por exemplo, Manoel de Barros preferir o termo "pássaro" àquele de "oiseau", embora tenham eles absolutamente o mesmo significado. Mas será, realmente? A isso responde, então, sem hesitação, o poema "Língua mãe" (Livros infantis). Talvez seja possível nele reconhecer um exemplo paradigmático daquele "ser-nomundo", de um estar-no-mundo que, ele sim, dá sentido às palavras, e não o contrário. Que se permita citá-lo aqui in extenso:

Não sinto o mesmo gosto nas palavras:

oiseau e pássaro.

Embora elas tenham o mesmo sentido.

Será pelo gosto que vem de mãe? de língua mãe?

Será por que eu não tenha amor pela língua

de Flaubert?

Mas eu tenho.

(Faço este registro porque tenho a estupefação

${ }^{27}$ BONNEFOY, 1990, p.144. 
de não sentir com a mesma riqueza as palavras oiseau e pássaro)

Penso que seja porque a palavra pássaro em mim repercute a infância

E oiseau não repercute.

Penso que a palavra pássaro carrega até hoje nela o menino que ia de tarde pra debaixo das árvores a ouvir os pássaros.

Nas folhas daquelas árvores não tinha oiseaux Só tinha pássaros.

É o que me ocorre sobre língua mãe. ${ }^{28}$

"Pássaro" e não "oiseau", pois que "oiseau $(x)$ " instauraria(m) um universo separado. E, como bem adverte Yves Bonnefoy, separar é uma falta. Cometida por poetas que se deixaram aprisionar pelas noções e que se isolam em uma linguagem que rompe com o mundo, em uma obra que se aparta do real e da presença, em geral, humilde, quase insignificante - no sentido primeiro e segundo do termo, aliás - das coisas. "Língua mãe" enunciaria justamente aquele poder da poesia de se prender àquilo que não pode ser nomeado com uma língua/linguagem "abstrata", isto é, e nos termos de Bonnefoy, "sem experiência direta das coisas do tempo, da finitude".${ }^{29}$ Necessidade de se aproximar, por isso mesmo, do simples e, essencialmente da terra com a qual nos relacionamos - da terra que, em Bonnefoy, é "lugar segundo" ou "lugar verdadeiro". Lugar verdadeiro pleno da "carga afetiva", lugar que carrega a "intensidade e a plenitude de que temos necessidade de nos lembrar". ${ }^{30}$ Lugar verdadeiro que acolhe e não rejeita, lugar verdadeiro que é lar. Como em "Qu'une place soit faite à celui qui approche", primeiro poema a integrar a sequência intitulada Vrai lieu:

${ }^{28}$ BARROS, 2010, p.475-476.

${ }^{29}$ BONNEFOY, 1990, p.225.

${ }^{30}$ BONNEFOY, 1990, p.225; p.227. 
Qu'une place soit faite à celui qui approche, Personnage ayant froid et privé de maison.

Personnage tenté par le bruit d'une lampe, Par le seuil éclairé d'une seule maison.

Et s'il reste recru d'angoisse et de fatigue, Qu'on redise pour lui les mots de guérison.

Que faut-il à ce coeur qui n'était que silence, Sinon des mots qui soient le signe et l'oraison.

Et comme un peu de feu soudain la nuit, Et la table entrevue d'une pauvre maison $?^{31}$

Lugar, casa, lar. Terra, ao final, terra com a qual o poeta consente, pois que pronunciada por uma "palavra descrucificada". Leiam-se, então, alguns versos de "La Terre", um dos poemas que compõem o célebre Dans le leurre du seuil:

Oui, moi les pierres du soir, illuminées, Je consens.

Oui, moi la flaque

Plus vaste que le ciel, l'enfant

Qui en remue la boue, l'iris

Aux reflets sans repos, sans souvenirs,

De l'eau, moi, je consens.

Et moi le feu, moi

La pupille du feu, dans la fumée

Des herbes et des siècles, je consens.

Moi la nuée

Je consens. Moi l'étoile du soir

${ }^{31}$ BONNEFOY, 1995, p.107. 
Je consens.

Moi les grappes de mondes qui ont mûri,

Moi le départ

Des maçons attardés vers les villages,

Moi le bruit de la fourgonnette qui se perd,

Je consens [...]

Moi le maillet

Qui heurta, à coups sourds,

Le ciel, la terre noire [...]

Moi le soleil,

Je m'arrête au faîte du monde dans les pierres.

Parole

Décrucifiée. Chanvre de l'apparence

Enfin rouie $[\ldots]^{32}$

\section{Quando tudo é pedra}

Ao leitor mais atento não terá passado despercebida a presença da pedra. Manoel de Barros, por exemplo, diz, em um dos quase aforismos de O Livro sobre nada que "queria ser lido pelas pedras"; 33 ele que, justamente, assim o diz em "Palavras", tem "precedência para pedra" ${ }^{34}$ Na produção poética manoelina e bonnefidiana, a pedra parece representar o fundamento, o solo mesmo da poesia. É para o que aponta o poema "Une pierre" do conjunto de poemas intitulado -presença e coisas-do/nomundo oblige-Pluies d'été:

Les livres, ce qu'il déchira,

La page dévastée, mais la lumière

Sur la page, l'accroissement de la lumière,

Il comprit qu'il devenait page blanche.

32 BONNEFOY, 1995, pp.295-297.

${ }^{33}$ BARROS, 2010, p.347.

${ }^{34}$ BARROS, 2010, p.477. 
Il sortit. La figure du monde, déchirée, Lui parut d'une beauté autre, plus humaine.

La main du ciel cherchait sa main parmi des ombres,

La pierre, où vous voyez que son nom s'efface, S'entrouvrait, se faisait une parole. ${ }^{35}$

É inegável que se lê e se inscreve aí o convite de abertura para um mundo, se não virgem, ao menos renovado, da poiesis. Convite para se fazer tábula rasa de tudo o que já foi dito, de romper com a Biblioteca de multisseculares repertórios e acervos e corpora; por isso mesmo, de (re)descobrir, pela ruptura, que é o apagamento do que existe que produz luz e a ela conduz. A pedra se faz palavra e não a palavra que se faz pedra, eis toda a lição, e toda nuança, que se depreende deste poema. Não surpreende, então, que em um dos poemas - ou mais propriamente um poema em prosa intitulado "Jeter des pierres" - recolhidos no célebre Les planches courbes, conte-se o momento em que um "nós", anteriormente "eles" nos poemas que o antecedem "Rouler plus vite" e "Rouler plus loin", ponham-se a jogar, a lançar pedras, em plena noite, em meio a uma atmosfera absolutamente feliz e ridente. Pedras que estão ali, "grandes pedras" retiradas do "mato", ao alcance das mãos, em meio à terra, constantemente escavada. Pedras lançadas longe, alhures, "do outro lado sem nome, no abismo onde não há nem alto nem baixo, nem barulho das águas nem estrela". ${ }^{36}$ São pedras que compõem, por conseguinte, um novo lugar, por sua vez construído sobre um "solo devastado".

Em Manoel de Barros, esse lugar é inegavelmente aquele do poético, essencialmente porque a poesia é "voz de poeta" que, por sua vez, "é voz de fazer nascimentos", isto é, de trazer ao mundo tudo aquilo que não tem nome e que está inscrito, inexoravelmente, nas pedras. E a essência do poeta confunde-se com o rés-do-chão,

${ }^{35}$ BONNEFOY, 2001, p.39.

${ }^{36}$ BONNEFOY, 2001, p.125. 
tanto mais porque o poeta, "pedra sendo", "[gosta] de jazer no chão" ${ }^{37} \mathrm{O}$ poietico é, no final das contas, um ser/estado-de-pedra. ${ }^{38}$ O poietico é, acima de tudo, em Manoel de Barros e em Yves Bonnefoy trabalhado por uma poética do ínfimo e do simples.

\section{Conclusão: para além da ruína das palavras}

Parece inegável que Manoel de Barros e Yves Bonnefoy põem em cena uma prática poética que busca se inscrever num registro para além dos signos, naquele que entende que as palavras "oferecem mais do que aquilo que é/Ou dizem outra coisa que aquilo que é" ${ }^{39}$ Tanto mais porque, afirma Manoel de Barros em "Caderno de andarilho", "elas foram feitas (todas as coisas) -/sem nome [...]". ${ }^{40}$ Impõe-se-lhes, entretanto, deambular por entre a ruína das palavras, poetas que são. Despenteando-as, desarrumando-as como fez Manoel de Barros; desescrevendoas, como fez Yves Bonnefoy em Le nuage rouge. O que significa que é incontornável entender, para concluir, como em tal projeto poético de desinvenção se desenha a relação com a imagem.

Em Yves Bonnefoy, ela revela-se mais conflituosa e, mesmo, ambivalente. Imagem que, em geral, caminha par e

${ }^{37}$ BARROS, 2010, p.405.

${ }^{38}$ Leia-se a este respeito, na íntegra, o poema "A Pedra" em Tratado geral da grandeza do infimo: "Pedra sendo/Eu tenho gosto de jazer no chão./Só privo com lagarto e borboletas./Certas conchas se abrigam em mim./De meus interstícios crescem musgos./Passarinhos me usam para afiar seus bicos./Às vezes uma garça me ocupa de dia./Fico louvoso./Há outros privilégios de ser pedra:/ a-Eu irrito o silêncio dos insetos. /b-Sou batido de luar nas solitudes. / c-Tomo banho de orvalho de manhã./d-E o sol me cumprimenta por primeiro" (BARROS, p.405). ${ }^{39}$ BONNEFOY, 2006, p.73 : " offrent plus que ce qui est/Ou disent autre chose que ce qui est[...]".

${ }^{40}$ BARROS, 2010, p.288. 
passo com a Ideia - uma e outra grafadas, não por acaso em seus escritos teóricos sobre o poético, em maiúscula. Donde a crítica bonnefidianna, que acusa Imagem e Ideia de se apartarem do mundo sensível e da finitude. O que em Bonnefoy parece se enunciar é a defesa do sensível contra a predominância do inteligível. Sua désécriture passaria, assim, necessariamente, pela denúncia da imagem que é, sempre, uma ficção, afastada da tão desejada "verdade da palavra". Como, então, essa désécriture - que é inegavelmente uma écriture - trabalha a recusa, a negação da imagem, consciente que é necessário, quiçá mesmo incontornável, consentir com seu uso? A resposta parece vir das observações que Yves Bonnefoy enuncia a respeito da poesia oriental em estilo breve conhecida como haïku - haicai em sua expressão lusófona. Segundo ele, os poetas japoneses teriam, com o haiku, logrado as expectativas de Mallarmé que "convocava uma prática de escritura no seio da qual 'o homem, em seguida sua autêntica estadia terrestre' partilharia palavra por palavra 'uma reciprocidade de provas' ${ }^{41}$ Graças ao haiku, reencontra-se "o imediato no seio mesmo da palavra", daquela palavra que, porque palavra, "logo à entrada abole o imediato". ${ }^{4}$ Os versos do haiku, "desenham a forma de um ser-no-mundo, e não aquela de um universo" ${ }^{43} \mathrm{O}$ haiku inscrever-se-ia assim no interior mesmo de um poético que desdenha "objetos de pensamento" trabalhados pela poesia ocidental e, ao contrário, privilegia, por exemplo, em sua própria insignificância, o crisântemo ou a "pequena rã que salta" sob a luz da lua. ${ }^{44}$

Não é precisamente essa insignificância - "O poema é antes de tudo um inutensílio" 45 - que permeia todo o trato

\footnotetext{
${ }^{41}$ BONNEFOY, 1990, p.134.

${ }^{42}$ BONNEFOY, 1990, p.142.

${ }^{43}$ BONNEFOY, 1990, p.144.

${ }^{44}$ BONNEFOY, 1990, p.134.

${ }^{45}$ BARROS, 2010, p.174.
} 
poético de Manoel de Barros com a imagem? O volume intitulado Poesia completa abre-se com uma "Entrada" - ao livro e à obra manoelina - que se oferece como que uma carta de intenções do projeto poético de Manoel de Barros. Ali se enuncia a relação do poeta com a imagem: a poesia, para ele, são "desenhos verbais de imagens", imagens que devem ser compreendidas não em toda sua pompa retórico-poética mas, justamente, na sua pertença ao mundo e às coisas; a poesia propriamente não significa, o que significa são o mundo e as coisas de que ela é desenho. A poesia é - e já é muito - carnação e encarnação:

[...] eu conversava bobagens profundas com os sapos, com as águas e com as árvores [...] A natureza avançava nas minhas palavras tipo assim: $\mathrm{O}$ dia está frondoso em borboletas. No amanhecer o sol põe glórias no meu olho. O cinzento da tarde me empobrece. E o rio encosta as margens na minha voz. Essa fusão com a natureza tirava de mim a liberdade de pensar. Eu queria que as garças me sonhassem. Eu queria que as palavras me gorjeassem. Então comecei a fazer desenhos verbais $[\ldots]{ }^{46}$

É o que se lê, como que a ratificar "Entrada", no poema XV de Arranjos para assobio:

[...] - Difícil de entender, me dizem, é a sua poesia, o senhor concorda?

- Para entender nós temos dois caminhos: o da sensibilidade que é o entendimento do corpo; e o da inteligência que é o entendimento do espírito.

Eu escrevo com o corpo

Poesia não é para compreender mas para incorporar Entender é parede: procure ser uma árvore. ${ }^{47}$

${ }^{46}$ BARROS, 2010, p.7.

${ }^{47}$ BARROS, 2010, p.178. 
O que significa dizer que a "-Poesia é a ocupação da palavra pela Imagem/- Poesia é a ocupação da Imagem pelo Ser" ${ }^{48}$ É graças, pois, à imagem que se assegura um lugar quase físico, quase corpóreo, ao Ser e aos Afetos.

\section{Referências bibliográficas}

BARROS, Manoel de. Poesia completa. Leya: São Paulo, 2010.

. Gramática Expositiva do Chão: poesia quase toda.

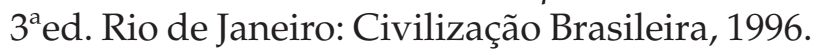

BONNEFOY, Yves. Entretiens sur la poésie (1972-1990). Paris: Mercure de France, 1990.

Gallimard, 1987.

. Rue Traversière et autres récits en rêve. Paris:

.Ce qui fut sans lumière. Paris: Gallimard, 1987a.

. L'improbable. Paris: Mercure de France, 1980.

. La Présence et l'Image. Paris: Seuil, 1999.

. L'Inachevable. Entretiens sur la poésie 1990-2010.

Paris: Albin Michel, 2010.

. Notre besoin de Rimbaud. Paris: Seuil, 2009.

Mercure de France, 1999a.

. Le nuage rouge. Dessin, couleur et lumière. Paris: . Les planches courbes. Paris : Gallimard, 2006.

RIMBAUD, Arthur. Poésies. Une saison en enfer. Illuminations. Paris: Gallimard, 1999.

VERLAINE, Paul. Art poétique. Paul Verlaine.Tournai : La Renaissance du Livre, 2004, p.6-7.

${ }^{48}$ BARROS, 2010, p.263. 


\section{Resumo}

Des-inventar o ato poético, ou des-escrever a poesia, eis a tarefa a que se dedicam, respectivamente, Manoel de Barros e Yves Bonnefoy. O poeta mato-grossense e o poeta francês, tão afastados no espaço, aproximam-se de modo inegável na reflexão que empreendem do ato poético: contrários a todo movimento de conceitualização e de gramaticalização que põe a perder a poesia, Manoel de Barros e Yves Bonnefoy propõem uma volta às origens, um regresso à fundação da palavra poética, a seu diálogo estreito com o mundo, com suas coisas e seus seres.

\section{Résumé}

Desinventar l'acte poétique ou désécrire la poésie: voici la tâche à laquelle se vouent respectivement Manoel de Barros et Yves Bonnefoy. Le poète du Mato Grosso et le poète français, bien qu'éloignés dans l'espace, s'approchent de manière indéniable par la réflexion qui proposent sur le faire poétique : contre tout mouvement de conceptualisation et de grammaticalisation qui font perdre la poésie, Manoel de Barros et Yves Bonnefoy proposent un retour aux origines, à la fondation de la parole poétique, au dialogue raproché avec le monde, ses choses et ses êtres. 